\title{
Characterization of ankylosing spondylitis in Upper Egypt
}

Objective: To explore the features of ankylosing spondylitis (AS) in Upper Egypt which has been under estimated in this area known for its lower socioeconomic status (SES).

Methods: Seventy patients with a definite diagnosis of AS were prospectively evaluated.Information about human leukocyte antigen (HLA-B27) status, pattern of axial and peripheral involvement, inflammatory markers, extra axial features and axial radiographic findings together with other demographic variables were recorded. Bath AS disease activity and functional status (BASDAI and BASFI) were also assessed.

Results: The mean age at onset was $24.9 \pm 7.5$ years and at diagnosis was $35.46 \pm 12.1$ years, with a diagnostic delay of 9.9 years on average. The male to female ratio was 2.9:1. HLA-B27 was positive in 38 of 51 patients (74.5\%). Eighteen patients (25.7\%) had a family history of AS. Peripheral arthritis was present in 14 patients (20\%). Anterior uveitis was present in 5 patients $(7.1 \%)$. The mean radiographic sacroiliitis grade was $2.42 \pm 0.59$. Lumbar syndesmophytes were present in 45 patients (64.3\%) and bamboo spine was present in 13 (18.6\%). Thirty (42.9\%) patients had radiographic hip abnormalities, of whom 6 had received hip replacement surgery. Of 65 patients examined by bone densitometry, osteoporosis was diagnosed in 26 patients (40\%). The mean BASDIA and BASFI were $4.8 \pm 1.18$ and $5.4 \pm$ 1.5 , respectively. Axial radiographic damage was significantly greater in men $(P>0.001)$. Only 6 patients (8.6\%) were aware of the nature of the disease and were maintained on regular treatment.

Conclusion: The characteristics of AS in Upper Egypt were revealed. Noticeable radiographic damage with a high BASFI and BASDAI indicated a more severe disease than that reported in other Middle Eastern populations with a higher SES.

Keywords: ankylosing spondylitis • upper Egypt $•$ HLA-B27

\section{Introduction}

Ankylosing spondylitis (AS) is a chronic inflammatory disease involving mainly the spine and sacroiliac joints, with variable extraarticular manifestations, including anterior uveitis, inflammatory bowel disease and cardiac abnormalities. Other complications include apical lung fibrosis, osteoporosis and amyloidosis. Peripheral joints may also be involved [1-3].

This rheumatic condition shows noticeable geographic and ethnic variations reflecting environmental and genetic interaction. The prevalence of the disease ranges from $0.0 \%$ to $1.8 \%$, depending on the population studied [4]. It is characterized as a disease of young adults typically starting in the second and third decades.
The male to female ratio shows varying estimates over populations, with a male predominance $[4,5]$.

A strong association exists between the HLA-B27 antigen and AS, which affects the prevalence and incidence rates of the disease. A study of a white population reported that $90 \%$ of patients carry the HLA-B27 antigen and estimated that approximately $20 \%$ of people carrying this antigen will develop AS [6].

Studies conducted in Middle Eastern and Arabic countries reported different estimates of this association with a generally lower prevalence of HLA-B27 than the worldwide value [7]. Environmental microbial and socioeconomicrelated factors, such as delayed diagnosis and

\section{Abdelhafeez Moshrif*1, Ahmed Mosallam', Mohamed Rayan', Hamed Khalifa ${ }^{2}$ \& Ali Sobhy ${ }^{3}$}

'Rheumatology department, Faculty of Medicine, Al-Azhar university, Assiut, Egypt.

2Public health department, Faculty of Medicine, Al-Azhar university, Assiut, Egypt.

${ }^{3}$ Clinical pathology department, Faculty of Medicine, Al-Azhar university, Assiut, Egypt.

${ }^{*}$ Author for correspondence: dr.moshrif@live.com 
therapeutic interventions, have been noted to impact the severity and prognosis of this debilitating disease $[8,9]$.

\section{Background}

Upper Egypt accounts for $40 \%$ of the country's population; however, $60 \%$ of residents live in poverty, $80 \%$ of whom live in severe poverty. More than half the population is under the age of 29, and one-third are between the ages of 15 and 29. Upper Egypt is predominantly rural, with $75 \%$ of its young people living in rural areas. The illiteracy rate for young people in Upper Egypt is $17 \%$, which is higher than the national average, and the illiteracy rate for females is more than twice that of males [10].

The aim of this prospective study was to clinically and radiographically characterize AS and to evaluate the disease severity and HLA-B27 association in Upper Egyptians.

\section{Methods}

In this single-center descriptive study, seventy patients with AS according to the modified New York criteria [11] were investigated. All patients were referred from different cities of Upper Egypt to be admitted and evaluated in our institution (a tertiary referral university hospital) after their acceptance of participation through written consent. The study was conducted from January 2015 to November 2016 and was approved by our university ethical committee for medical research.

A detailed history, including age, sex, occupation, educational status, residence (urban or rural), smoking, age at onset of symptoms and at diagnosis, diagnosing physician (rheumatologist, orthopedist or general practitioner), drug history and all related symptomatology analysis, was performed. A complete physical examination, including the assessment of the disease activity status and physical function using an Arabic translated version of the Bath AS disease activity index (BASDAI) and the Bath AS functional index (BASFI), was performed. Assessment of spinal mobility using the modified Schober test and tragus to wall and chest expansion measures was performed. Body mass index (BMI) was calculated according to World Health Organization classification: weight in $\mathrm{kg} /$ height in $\mathrm{m}^{2}$. Echocardiographic and slit lamp examinations were performed for all patients.

It would be better to stratify our patients according to SES but this was not practically possible due to the very similar levels of financial income.

\section{Radiographic examinations}

In collaboration with the radiology department, conventional radiography for sacroiliac joints was graded according to the modified New York grading system $(0=$ normal to $4=$ complete ankylosis) through a consensus of the participating rheumatologists. Lumbo-sacral and cervical spine radiography was also evaluated for the presence of vertebral squaring, shiny corners, syndesmophytes and bamboo spine. Radiographic evaluations of shoulder and hip joints were performed to detect any abnormalities in the case of clinical symptoms. The bone mineral density (BMD) of 65 patients was evaluated using dual energy X-ray absorptiometry (DXA) (Lunar DPX densitometer, General Electric, 2012, USA) at the postero-anterior (PA) lumbar spine (L1-L4), femoral neck and distal radius. Patients were diagnosed according to the World Health Organization classification as normal ( $T$ score $\geq-1$ ), osteopenia ( $T$ score between -1 and $-2.5)$ or osteoporosis (T score $\leq-2.5)$ [12]. The lowest $\mathrm{T}$ score of the three areas was considered for interpretation.

\section{Laboratory investigations}

Five milliliters of venous blood was collected from each patient; $2 \mathrm{ml}$ was collected in a tube containing EDTA for determination of the erythrocyte sedimentation rate (ESR) by the Westergren method, and $3 \mathrm{ml}$ was used to determine the C-reactive protein (CRP) level using the latex agglutination test.

Assessment of HLA B27: Blood samples were collected from 51 patients, and serum samples were then subdivided into small aliquots to be stored at $-80^{\circ} \mathrm{C}$ until tested for human HLA B27 (Sunlong Biotech, catalog number: SL1056Hu). Standards and samples were pipetted into the wells and HLA B27 present in a sample was bound to the wells by the immobilized antibody. The wells were washed and biotin labeled anti-HLA B27 antibody was added. After washing away unbound biotinylated antibody, HRP-conjugated streptavidin was pipetted to the wells. The wells are again washed, a TMB substrate solution was added to the wells and color develops in proportion to the amount of HLA B27 bound. The Stop solution changes the color from blue to yellow, and the intensity of the color was measured at $450 \mathrm{~nm}$. 


\section{Statistical analysis}

The collected data were revised, tabulated and analyzed using SPSS V22.0 for Windows (SPSS Inc., Chicago, Illinois, USA). Quantitative variables are expressed as means \pm standard deviations (SD), and qualitative variables are expressed as numbers and percentages. Quantitative variables with a normal distribution were analyzed using the Shapiro-Wilk test. Differences between independent groups were assessed by Student's t-test for normally distributed quantitative variables, and the MannWhitney $U$ test was used to assess variables without a normal distribution, if present. The chi-square test and Fisher's exact test were used to assess differences between independent groups for qualitative variables. All results were considered statistically significant at the level of $\mathrm{P}<0.05$.

\section{Results}

\section{Demographics}

During a two-year period, 70 patients were enrolled. The mean disease duration was 12.97 \pm 9.1 year. The participants included 52 males $(74.3 \%)$ and 18 females $(25.7 \%)$. The male to female ratio was 2.9:1. The mean age at onset of symptoms was $24.9 \pm 7.5$ years, and the mean age at diagnosis was $35.46 \pm 12.1$ years with a diagnostic delay of approximately 9.9 years on average. Men and women differed in the mean age at onset $(26.15 \pm 7.5$ vs. $21.7 \pm 6.5$, $\mathrm{P}=0.032)$, mean age at diagnosis $(37.7 \pm 12.6$ vs. $29.2 \pm 8.06, \mathrm{P}=0.012)$, mean disease duration
$(14.85 \pm 9.5$ vs. $7.65 \pm 4.8, \mathrm{P}=0.004)$ and average diagnostic delay (10.9 vs. 7.4, $\mathrm{P}=0.032$ ).

Of all patients, only 19 (27.1\%) were highly educated (university level or above), and 41 patients $(58.6 \%)$ were smokers. Most of our patients $(84.3 \%)$, including all women, were diagnosed by rheumatologists, which reflects the lack of awareness of the disease in other specialties including orthopedists. The demographic features are presented in Table 1.

\section{Clinical characteristics}

At the time of evaluation, all patients had a history of inflammatory low back pain and clinical sacroiliitis, while 64 (91.4\%) patients had fatigue. Familial AS was noted in 18 patients $(25.7 \%)$, in addition to one patient with family history of psoriasis. All patients had limited spinal mobility. The mean modified Schober test value was $2.09+0.63$, the mean tragus to wall distance was $14.7 \pm 6.6$, and the mean chest expansion was $3.2 \pm 0.83$. Peripheral arthritis was recorded in 14 patients $(20 \%)$, with the knee joint most frequently involved, followed by the wrist and the ankle joints. Two patients had rheumatoid-like arthritis involving the small joints of the hands and feet. Bilateral hip arthritis was found in 33 patients $(47.1 \%)$, while 5 patients had unilateral hip involvement. The shoulder joint was involved in 16 patients $(22.8 \%)$. Clinical enthesitis was found in 27 patients (38.6\%), involving the plantar area in $15(21.4 \%)$ patients and both the Achilles and plantar insertions in 8 (11.4\%) patients, while 4 patients $(5.7 \%)$ had isolated

\begin{tabular}{|c|c|c|c|c|}
\hline Variable & All patients $\mathrm{No}=70$ & Male No=52 & Female $\mathrm{No}=18$ & $P$ value \\
\hline Age & $37.95 \pm 13.162$ & $41.2 \pm 13.3$ & $29.4 \pm 8.03$ & $<0.0001 \mathrm{~S}^{*}$ \\
\hline \multicolumn{5}{|c|}{ Marital status } \\
\hline Married & $52(74.3 \%)$ & $40(77 \%)$ & $12(66.7 \%)$ & \multirow[t]{2}{*}{$0.39 \mathrm{NS}^{* *}$} \\
\hline Single & $18(25.7 \%)$ & $12(23 \%)$ & $6(33.3 \%)$ & \\
\hline \multicolumn{5}{|c|}{ Education } \\
\hline High & $19(27.1 \%)$ & $11(21.1 \%)$ & $8(44.4 \%)$ & \multirow{2}{*}{$0.52 \mathrm{NS}^{* *}$} \\
\hline Low & $51(72.8 \%)$ & $41(78.8 \%)$ & $10(55.6 \%)$ & \\
\hline \multicolumn{5}{|c|}{ Body mass index } \\
\hline Normal & $44(60.6 \%)$ & $33(63.4 \%)$ & $11(61.1 \%)$ & \multirow{3}{*}{$0.81 \mathrm{NS}^{* * *}$} \\
\hline Overweight & $20(30.3 \%)$ & $14(26.9 \%)$ & $6(33.3 \%)$ & \\
\hline Obese & $6(9.1 \%)$ & $5(9.6 \%)$ & $1(5.6 \%)$ & \\
\hline \multicolumn{5}{|c|}{ Smoking } \\
\hline Smokers & $41(58.6 \%)$ & $41(78.8 \%)$ & $0(0 \%)$ & \multirow[t]{2}{*}{$<0.001 \mathrm{~S}^{* * *}$} \\
\hline Non smokers & $29(41.4 \%)$ & $11(21.1 \%)$ & $18(100 \%)$ & \\
\hline \multicolumn{5}{|c|}{ Residence } \\
\hline Rural & $59(84.2 \%)$ & $48(92.3 \%)$ & $11(61.1 \%)$ & \multirow{2}{*}{$0.007 \mathrm{~S}^{* * *}$} \\
\hline Urban & $11(15.7 \%)$ & $4(7.7 \%)$ & $7(38.9 \%)$ & \\
\hline
\end{tabular}


Achilles tendon enthesitis. Ocular examination revealed anterior uveitis in 5 patients $(7.1 \%)$, and echocardiography revealed a dilated aortic root in one patient, while another patient had ulcerative colitis diagnosed by colonoscopy. Of 65 patients examined by DXA, osteoporosis was diagnosed in 26 patients (37.1\%), and osteopenia was diagnosed in $25(35.7 \%)$ patients. Twentytwo patients $(31.4 \%)$ had kyphosis. The mean BASFI and BASDAI values were $5.4 \pm 1.5$ and $4.8 \pm 1.18$, respectively, while the mean CRP level and ESR were $14.12 \pm 14.4$ and $40.5 \pm$ 28.8 , respectively. HLA-B27 was evaluated in 51 patients and found to be positive in 38 (74.5\%). No significant difference was observed between men and women, except for the mean modified
Schober test score $(1.96 \pm 0.79$ vs. $2.44 \pm 0.7$, $\mathrm{P}=0.026)$ and the presence of clinical enthesitis $(\mathrm{P}=0.041)$, kyphosis $(\mathrm{P}=0.021)$ and osteoporosis $(\mathrm{P}=0.002)$. The clinical characteristics are presented in Table 2.

\section{Radiographic abnormalities}

Radiographic examination revealed sacroiliitis in all patients (mean grade $2.42 \pm 0.59$ ) and lumbar and cervical syndesmophytes in 45 (64.3\%) and 35 (50\%) patients, respectively. Bamboo spine was detected in 13 patients (12 men). Radiographic hip joint abnormalities were detected bilaterally in 20 patients $(28.6 \%)$ and unilaterally in $10(14.3 \%)$ patients, and abnormalities consisted of joint space

Table 2. Clinical features of patients according to sex.

\begin{tabular}{|c|c|c|c|c|}
\hline Parameter & $\begin{array}{c}\text { All patients } \\
\text { No }=70\end{array}$ & Male $\mathrm{No}=52$ & Female No $=18$ & $P$ value \\
\hline Disease duration ( Mean \pm SD) & $12.97 \pm 9.1$ & $14.85 \pm 9.5$ & $7.65 \pm 4.8$ & $0.004 S^{*}$ \\
\hline Age at onset ( Mean \pm SD) & $24.9 \pm 7.5$ & $26.15 \pm 7.5$ & $21.7 \pm 6.5$ & $0.032 \mathrm{~S}^{*}$ \\
\hline Age at diagnosis ( Mean \pm SD) & $34.9 \pm 12.1$ & $37.04 \pm 12.8$ & $29.1 \pm 7.84$ & $0.017 S^{*}$ \\
\hline Diagnostic delay( Mean \pm SD) & $9.9 \pm 7.7$ & $10.9 \pm 8.5$ & $7.4 \pm 4.3$ & $0.032 \mathrm{~S}^{*}$ \\
\hline Diagnosed by rheumatologist & $59(84.3 \%)$ & $41(78.8 \%)$ & $18(100 \%)$ & $0.96 \mathrm{NS}^{* *}$ \\
\hline Family history of AS & $18(25.7 \%)$ & $16(30.8 \%)$ & $2(11.1 \%)$ & $0.11 \mathrm{NS}^{* *}$ \\
\hline Fatigue & 64(91.4\%) & $46(88.4 \%)$ & $18(100 \%)$ & $0.53 \mathrm{NS}^{* * *}$ \\
\hline \multicolumn{5}{|c|}{ Clinical sacroiliitis } \\
\hline Bilateral & $70(100 \%)$ & $52(100 \%)$ & $18(100 \%)$ & $\mathrm{N} / 0^{+}$ \\
\hline Modified Schober test (Mean \pm SD) & $2.09 \pm 0.79$ & $1.96 \pm 0.79$ & $2.44 \pm 0.7$ & $0.026 \mathrm{~S}^{*}$ \\
\hline Tragus to wall distance ( Mean \pm SD) & $14.7 \pm 6.61$ & $15.52 \pm 6.63$ & $12.5 \pm 6.2$ & $0.099 \mathrm{NS}^{* *}$ \\
\hline Chest expansion (Mean \pm SD) & $3.2 \pm 0.83$ & $3.08 \pm 0.82$ & $3.5 \pm 0.78$ & $0.068 \mathrm{NS}$ \\
\hline Kyphosis & $22(31.4 \%)$ & $20(38.5 \%)$ & $2(11.1 \%)$ & $0.021 \mathrm{~S}^{* *}$ \\
\hline Clinical shoulder affection & $16(22.8 \%)$ & $14(26.9 \%)$ & $2(11.1 \%)$ & $0.11 \mathrm{NS}$ \\
\hline \multicolumn{5}{|c|}{ Clinical hip affection } \\
\hline Bilateral & $33(47.1 \%)$ & $26(50 \%)$ & $7(38.9 \%)$ & \multirow[t]{2}{*}{$0.53 \mathrm{NS}^{* *}$} \\
\hline Unilateral & $5(7.14 \%)$ & $3(5.8 \%)$ & $2(11.1 \%)$ & \\
\hline Peripheral arthritis(current or history) & $14(20 \%)$ & $12(23 \%)$ & $2(11.1 \%)$ & $0.32 \mathrm{NS}^{* *}$ \\
\hline Clinical enthesitis & $27(38.6 \%)$ & $16(30.8 \%)$ & $11(61.1 \%)$ & $0.041 \mathrm{~S}^{* * *}$ \\
\hline Chest wall pain/tenderness & $53(75.7 \%)$ & $38(73.1 \%)$ & $15(83.3 \%)$ & $0.7 \mathrm{NS}$ \\
\hline Anterior uveitis & $5(7.1 \%)$ & $5(9.6 \%)$ & $0(0 \%)$ & $0.31 \mathrm{NS}^{* *}$ \\
\hline Ulcerative colitis & $1(1.4 \%)$ & $0(0 \%)$ & $1(5.6 \%)$ & $0.27 N S^{* *}$ \\
\hline Aortic root dilatation & $1(1.4 \%)$ & $1(1.9 \%)$ & $0(0 \%)$ & $0.72 \mathrm{NS}^{* *}$ \\
\hline \multicolumn{5}{|c|}{$\mathrm{BMD}(\mathrm{No}=65)$} \\
\hline Osteoporosis & $26(37.1 \%)$ & $24(46.2 \%)$ & $2(11.8 \%)$ & $0.0029 \mathrm{~S}^{* *}$ \\
\hline Osteopenia & $25(35.7 \%)$ & $17(32.7 \%)$ & $8(47.1 \%)$ & $0.2 \mathrm{NS}^{* *}$ \\
\hline \multicolumn{5}{|c|}{ HLA-B27 $(\mathrm{No}=51)$} \\
\hline Positive & $38(74.5 \%)$ & $29(72.5 \%)$ & $9(81.8 \%)$ & \multirow[t]{2}{*}{$0.7 \mathrm{NS}^{* *}$} \\
\hline Negative & $13(25.5 \%)$ & $11(27.5 \%)$ & $2(18.2 \%)$ & \\
\hline BASFI (Mean \pm SD) & $5.4 \pm 1.5$ & $5.6 \pm 1.6$ & $4.8 \pm 1.1$ & $0.53 \mathrm{NS}^{*}$ \\
\hline BASDAI (Mean \pm SD) & $4.8 \pm 1.18$ & $4.8 \pm 1.14$ & $4.8 \pm 1.3$ & $0.87 \mathrm{NS}^{*}$ \\
\hline CRP $($ Mean \pm SD $)$ & $14.12 \pm 14.4$ & $15.5 \pm 16.07$ & $10.5 \pm 7.7$ & $0.21 \mathrm{NS}^{*}$ \\
\hline ESR $($ Mean $\pm S D)$ & $40.5 \pm 28.8$ & $40 . \pm 30.2$ & $41.4 \pm 25.7$ & $0.86 \mathrm{NS}^{*}$ \\
\hline \multicolumn{5}{|c|}{$\begin{array}{l}\text { AS ankylosing spondylitis, BMD bone mineral density, HLA-B27 human leukocyte antigen-B27, BASFI Bath ankylosing } \\
\text { spondylitis functional index, BASDAI Bath ankylosing spondylitis disease activity index, CRP C-reactive protein, ESR } \\
\text { erythrocyte sedimentation rate*Independent sample t-test, ** Fisher's exact, ***. Chi-square test S significant, NS } \\
\text { non -significant }\end{array}$} \\
\hline
\end{tabular}


narrowing associated with osteonecrosis in $5(7.4 \%)$ patients. Six patients $(8.6 \%)$ had a history of hip joint replacement, with bilateral replacement in 2 patients. A significant male predominance was observed regarding lumbar and cervical syndesmophytes $(\mathrm{P}=0.011$ and 0.012 , respectively). Radiographic abnormalities are shown in Table 3.

\section{Treatment}

Forty-nine patients (70\%) used non-steroidal anti-inflammatory drugs (NSAIDs) irregularly as analgesic treatment, and six patients were controlled by regular use of NSAIDs, mostly consisting of diclofenac. Eight patients with peripheral arthritis used NSAIDs and DMARDs (6 used salazopyrin and 2 used methotrexate). Although 18 patients of those followed up were indicated to receive biologic treatment according to international guidelines [13], only 3 could be started on etanercept for a short period of time due to financial disability and a lack of governmental insurance. Lack of awareness existed among patients $(91 \%)$ regarding adherence to treatment and the natural history and possible outcome of the disease (Table 4).

\section{Discussion}

This is the first study to describe AS in Upper Egypt, an area known for its low SES. The number of patients recruited during the period of study in a single center reflects a higher prevalence of the disease than that reported for other Middle Eastern populations, such as Saudi Arabia (15 patients over 5 years) [14], Qatar (4 Qatari patients among 25 Arabic patients over one year) [15] and North Jordan (22 patients over 4 years) [16].

The male to female ratio in this study was 2.9:1, which is similar to previous reports denoting a male predominance with variable ratios ranging from 2.8:1 in Saudi Arabia [14] to 10:1 in Jordan [17].

The age of onset was previously thought to impact disease severity [18]. We found a mean age of onset of 24.9 years, which was similar to that reported in most studies. The age of onset in previous studies was 24.1 years in Egypt [19], 23.4 years in Saudi Arabia [14], 26 years in Jordan [20], 25.1 years in Morocco [9], 25.9 years in Qatar [15] and 22.3 years in Syria [21]. However, another Egyptian study reported an age of onset of 29.6 years [22].

The diagnostic delay in the current study (9.9 years) was much higher than that reported previously for other Middle Eastern populations [14,15,23-25]. However, an Italian study [26] reported a diagnostic delay of approximately 9 years, and another recent study from North

Table 4. Treatment received by ankylosing spondylitis patients.

\begin{tabular}{|c|c|}
\hline Treatment received & AS patients $(70)$ \\
\hline Regular NSAIDs & $6(8.6 \%)$ \\
\hline Irregular NSAIDs & 49 (70\%) \\
\hline NSAIDs+DMARDs & $8(11.4 \%)$ \\
\hline Biololgic drugs & $3(4.3 \%)$ \\
\hline \multicolumn{2}{|c|}{$\begin{array}{c}\text { NSAIDs: Non-steroidal anti-inflammatory drugs, } \\
\text { DMARDs: Disease modifying anti-rheumatic drugs, AS: } \\
\text { Ankylosing spondylitis. }\end{array}$} \\
\hline
\end{tabular}

\begin{tabular}{|c|c|c|c|c|}
\hline Variables & All patients $\mathrm{No}=\mathbf{7 0}$ & Male No=52 & Female $\mathrm{No}=18$ & $P$ value \\
\hline $\begin{array}{l}\text { Rdiographic sacroiliitis Grade(Mean } \\
\qquad \pm \text { SD) }\end{array}$ & $2.42 \pm 0.59$ & $2.35 \pm 0.56$ & $2.6 \pm 0.63$ & $0.12 \mathrm{NS}^{*}$ \\
\hline Vertebral Squaring & $49(70 \%)$ & $33(63.5 \%)$ & $16(88.9 \%)$ & $0.12 \mathrm{NS}^{* *}$ \\
\hline Shiny corners & $53(75.7 \%)$ & $37(71.2 \%)$ & $16(88.9 \%)$ & $0.94 \mathrm{NS}^{* *}$ \\
\hline Lumbar syndesmophytes & $45(64.3 \%)$ & $37(71.2 \%)$ & $8(44.4 \%)$ & $0.011 \mathrm{~S}^{* *}$ \\
\hline Cervical syndesmophytes & $35(50 \%)$ & $30(57.7 \%)$ & $5(27.8 \%)$ & $0.012 \mathrm{~S}^{*}$ \\
\hline Bamboo spine & $13(18.6 \%)$ & $12(23 \%)$ & $1(5.6 \%)$ & $0.1 \mathrm{NS}^{* * *}$ \\
\hline \multicolumn{5}{|c|}{ Radiographic shoulder abnormalities } \\
\hline Bilateral & $2(2.85 \%)$ & $2(3.85 \%)$ & 0 & \multirow[t]{2}{*}{$0.73 \mathrm{NS}^{* * *}$} \\
\hline Unilateral & $2(2.85 \%)$ & $1(1.9 \%)$ & $1(5.6 \%)$ & \\
\hline \multicolumn{5}{|c|}{ Radiographic hip abnormalities } \\
\hline Bilateral & $20(28.6 \%)$ & $17(32.7 \%)$ & $3(16.7 \%)$ & \multirow[t]{2}{*}{$0.09 \mathrm{NS}^{* * *}$} \\
\hline Unilateral & $10(14.3 \%)$ & $8(15.4 \%)$ & $2(11.1 \%)$ & \\
\hline Hip osteonecrosis & $5(7.4 \%)$ & $4(7.7 \%)$ & $1(5.6 \%)$ & $1.0 \mathrm{NS}^{* * *}$ \\
\hline Bilateral Hip Replacement & $2(2.85 \%)$ & $1(1.9 \%)$ & $1(5.6 \%)$ & \multirow[t]{2}{*}{$1.0 \mathrm{NS}^{* * *}$} \\
\hline Unilateral Hip Replacement & $4(5.7 \%)$ & $4(7.7 \%)$ & $0(0 \%)$ & \\
\hline \multicolumn{5}{|c|}{ *Independent sample t-test, ${ }^{* *}$ Chi-square test, ${ }^{* * *}$ Fisher's exact. S significant, NS non-significant } \\
\hline
\end{tabular}


West England [27] showed a diagnostic delay of approximately 10.1 years, thus indicating that diagnosis is still a challenge worldwide.

This delay in our study can be explained by the lack of rheumatologists, and the lack of awareness among general practitioners and orthopedists about AS, as most of the patients in this series were diagnosed by rheumatologists $(84.3 \%)$. Furthermore, the rural residence of most of our patients and the low SES could be considered as causes of delayed consultation. The age of onset, age at diagnosis, disease duration and diagnostic delay were significantly higher in men than in women in our study. This is inconsistent with the findings of an Iranian study that reported a higher, but not significant, mean of these variables in women than in men [28]. Additionally, a previous Moroccan study reported findings completely opposite to our results regarding the age at onset [9].

We found no significant difference between genders for family history. A similar finding was also reported by previous studies from Turkey [24] and Iran [28], while a Moroccan study reported a more prevalent family history in women [9].

The ASAS-COMOSPA study [29] involved 224 Egyptian patients with spondyloarthritis, of whom $17 \%$ were smokers and 59\% were highly educated. However, in our study, the percentage of smokers was $58.6 \%$, and the percentage of highly educated patients was only $27.1 \%$. Another Egyptian study [19] on spondyloarthritis reported that $12.5 \%$ of patients were highly educated and $23.2 \%$ were smokers, indicating a socioeconomic variation among the Egyptian regions.

Hip joint involvement in our study (54.3\%) was higher than that reported in the Moroccan study (47.3\%) [9] and the Jordanian study (9\%) [16]. We found no significant difference between men and women regarding hip involvement. However, an Iranian study reported an involvement rate of $87.4 \%$ with a higher frequency in men, although this result was not statistically significant [28]. Notably, $6(8.6 \%)$ of our patients $(5 \mathrm{men})$ had undergone hip joint replacement, and 5 others had osteonecrosis at the time of evaluation.

Peripheral arthritis was found in 20\% of our study participants, which is lower than the reported percentage of other Middle Eastern populations. The rates of peripheral arthritis were $34 \%$ in Jordanians [7], 36.2\% in Moroccans [9], $33 \%$ in Saudis [14] and 46.8\% in those living in Qatar [15], while the rate was much higher among Iranians (63.2\%) [23].

Among the extra-articular manifestations, anterior uveitis was the most commonly reported, with a rate of $7.1 \%$ in this study, which was similar to that reported among Moroccans (6.8\%) [9] and Saudis (7\%) [14] but lower than that reported in Jordanians (13\%) [16], Kurdish (12.2\%) [30], Iranians (44.9\%) [23] and those living in Qatar (14.5\%) [15].

Radiographic spinal involvement was noted in all patients of this series, of which $64.3 \%$ had lumbar syndesmophytes and 13 patients (18.6\%) had bamboo spine. These findings were higher than those reported among Moroccans (37.7\% and $12.7 \%$ ) [9], Jordanians (4.5\% for bamboo spine) [16], Kuwaitis $(30.9 \%$ and 13\%) [25] and those living in Qatar (32.7\%, $12.5 \%$ ) [15]. The ASAS-COMOSPA study reported the highest prevalence of bamboo spine among Egyptians (25\%) compared to the other populations studied [29]. We noted that 11 of 13 patients with bamboo spine had destructive hip arthropathy, which is consistent with previous studies that found a strong correlation between hip involvement and severe axial disease [31].

When the lowest $\mathrm{T}$-score of the examined sites was considered, the prevalence rates of osteoporosis and osteopenia were $37.1 \%$ and $35.7 \%$, respectively, in our patients and were higher in men. The previously mentioned ASASCOMOSPA study [29] reported osteoporosis in $7 \%$ of Egyptians and a prevalence ranging from $4 \%$ in Belgium to $29 \%$ in Russia.

The parameters of disease activity and functional disability in this study (BASDAI and BASFI) were comparable to those reported in two previous Egyptian studies [19,22] but higher than those reported in studies from Qatar [15], Iran [23] and Turkey [32]. This finding reflects the severity of the disease in our area, which could be attributed to delayed diagnosis and improper treatment, as well as the high cost of biologic drugs, as previously stated [19].

The association of HLA-B27 with AS has been estimated to vary among different ethnic populations. HLA-B27 prevalence among AS patients in the Arab populations is generally lower than the worldwide value, which ranges from 56 to $84 \%[7,33,34]$. Three previous Egyptian studies reported positivity rates of $58.6 \%$ [19], $82 \%$ [22], and $86.7 \%$ [35]. In the current study, HLA-B27 was positive in $74.5 \%$ 
of patients tested. The prevalence rates were $67 \%$ in Saudi Arabia [14], 72\% in Jordan [7], 82.6\% in Kuwait [25], 82\% in Qatar [34], 73.4\% in Iran [23], 67\% in Morocco [36] and 70\% in Turkey [37]. However, the prevalence rates were higher in northern Europe (90\%) [38] and Spain (94.3\%) [39].

\section{Conclusion}

This study provided a descriptive analysis of the clinical and radiographic patterns of AS and its association with HLA-B27 in Upper Egypt. The lower SES of this area seems to have a great impact on the diagnosis and management of AS. Radiographic abnormalities in the spine and hip joints, together with the high disease activity and functional disability indices, were significant among our patients and reflected a more severe disease than that reported in other Middle Eastern populations.

\section{Acknowledgement}

The authors would like to thank Professor Dr. Basel El Zorkany, Professor of Rheumatology, Cairo University and member of ASAS, for his valuable instructions during the performance of this work and Dr. Amin Abdelhamid, lecturer of rheumatology, Al Azhar university, for his participation in the design and his beneficial instructions throughout the study.

\section{Conflict of Interest}

The authors declare that they have no competing interest.

Informed consent

Informed consent was obtained from all individual participants included in the study.

\section{Ethical approval}

All procedures performed in the study were in accordance with the ethical standards of the institutional research committee and with the 1964 Helsinki Declaration and its later amendments or comparable ethical standards.

\section{References}

1. Khan M. Ankylosing spondylitis: clinical aspects. The spondylarthritides. Oxford, England: Oxford University Press. (1998).

2. van der Linden S, van der Heijde D. Ankylosing spondylitis- Clinical features. Rheum. Dis. Clin. North. Am. 24, 663-676 (1998).

3. Stolwijk C, Essers I, van Tubergen A et al. The epidemiology of extra-articular manifestations in ankylosing spondylitis: a population-based matched cohort study. Ann. Rheum. Dis. 74(7), 1373-8 (2015).

4. Sieper J, Rudwaleit M, Khan MA et al. Concepts and epidemiology of spondyloarthritis. Best. Pract. Res. Clin. Rheumatol. 20(3), 401-417 (2006).

5. Will R, Edmunds L, Elswood J et al. Is there sexual inequality in ankylosing spondylitis? A study of 498 women and 1202 men. J. Rheumatol. 17, 1649-1652 (1990).
6. Calin A, Fries JF. The striking prevalence of ankylosing spondylitis in "healthy" w27 males and females: a controlled study. N. Engl. J. Med. 293, 835-39 (1975).

7. Otom A, Al-Ahmar MR. HLA-B27 and ankylosing spondylitis in Jordan. GARJMMS. 2(12), 252-5 (2013).

8. Zochling J, Bohl-Bühler MH, Baraliakos X et al. Infection and work stress are potential triggers of ankylosing spondylitis. Clin. Rheumatol. 25(5), 660-66 (2006).

9. El Mansouri L, Bahiri R, Abourazzak F et al. Two distinct patterns of ankylosing spondylitis in Moroccan patients. Rheumatol. Int. 29(12), 1423-9 (2009).

10. Egypt Network for Integrated Development. A Profile of Poverty Across Egypt and Recommendations. Policy Brief 015 .

11. Van der Linden S, Valkenburg HA, Cats A. Evaluation of diagnostic criteria for ankylosing spondylitis. A proposal for modification of the New York criteria. Arthritis. Rheum. 27, 361-368 (1984).

12. World Health Organization. Assessment of fracture risk and its application to screening for postmenopausal osteoporosis. WHO Technical Report Series 843. Geneva (1994).

13. Van der Heijde D, Sieper J, Maksymowych WP et al. Update of the international ASAS recommendations for the use of anti-TNF agents in patients with axial spondyloarthritis. Ann. Rheum. Dis. 70(6), 905-8 (2011).

14. Al-Arfaj A. Profile of ankylosing spondylitis in Saudi Arabia. Clin. Rheumatol. 15(3), 287-9 (1996).

15. Alam F, Qaid Lutf A, Abdulla N et al. Characteristics of Ankylosing Spondylitis patients living in Qatar. The Egyptian Rheumatologist. 39(2) (2016).

16. Askari A, Al-Bdour M, Saadeh A et al. Ankylosing spondylitis in north Jordan: descriptive and analytical study. Ann. Rheum. Dis. 59, 571-573 (2000).

17. Mustafa KN, Hammoudeh M, Khan MA. HLA-B27 Prevalence in Arab populations and among patients with ankylosing spondylitis. J. Rheumatol. 39, 1675-7 (2012).

18. Robertson LP, Davis MJ. A longitudinal study of disease activity and functional status in a hospital cohort of patients with ankylosing spondylitis. Rheumatology. 43, 1565-1568 (2004).

19. Tayel MY, Soliman E, El Baz WF et al. Registry of the clinical characteristics of spondyloarthritis in a cohort of Egyptian population. Rheumatol. Int. 32(9), 2837-42 (2012).

20. Al-Amayreh IA, Zaidat BO. Ankylosing spondylitis in Northern Jordan. Saudi. Med. J. 21(10), 950-2 (2000).

21. Harfouch EI, Al-Cheikh SA. HLA-B27 and its subtypes in Syrian patients with ankylosing spondylitis. Saudi. Med. J. 32(4), 364-368 (2011).

22. Sayed S, Darweesh H, Fathy K et al. Clinical significance of bone mineral density in Ankylosing Spondylitis patients: Relation to disease activity and physical function. The Egyptian Rheumatologist. 37(1), 35-9 (2015).

23. Nazarinia MA, Ghaffarpasand F, Heiran HR et al. Pattern of ankylosing spondylitis in an Iranian population of 98 patients. Mod. Rheumatol. 19(3), 309-15 (2009). 
24. Bodur H, Ataman S, Bugdayci DS et al. Description of the registry of patients with ankylosing spondylitis in Turkey: TRASD-IP. Rheumatol. Int. 32(1), 169-176 (2012).

25. Uppal SS, Abraham M, Chowdhury RI et al. Ankylosing spondylitis and undifferentiated spondyloarthritis in Kuwait: a comparison between Arabs and South Asians. Clin. Rheumatol. 25(2), 219-24 (2006).

26. Salvadorini G, Bandinelli F, Delle Sedie A et al. Ankylosing spondylitis: how diagnostic and therapeutic delay have changed over the last six decades. Clin. Exp. Rheumatol. 30, 561-5 (2012).

27. Martindale J, Goodacre L. The journey to diagnosis in AS/axial SpA: the impact of delay. Musculoskeletal Care. 12, 221-31 (2014)

28. Shahlaee A, Mahmoudi M, Nicknam MH et al. Gender differences in Iranian patients with ankylosing spondylitis. Clin. Rheumatol. 34(2), 285-93 (2015).

29. Moltó A, Etcheto A, van der Heijde D et al. Prevalence of comorbidities and evaluation of their screening in spondyloarthritis: results of the international crosssectional ASAS-COMOSPA study. Ann. Rheum. Dis. 75(6), 1016-23 (2015)

30. Al-Qadi R, Salih SF, Aldosoki HJ et al. Association between HLA-B27 with ankylosing spondylitis in Kurdish patients. Int. J. Rhum. Dis. 20(8), 980-984 (2015).

31. Jang JH, Ward MM, Rucker AN et al. Ankylosing spondylitis: patterns of radiographic involvement - a reexamination of accepted principles in a cohort of 769 patients. Radiology. 258, 192-198 (2011).
32. Solmaz D, Cetin P, Pamuk ON et al. The Impact of Ankylosing Spondylitis in Turkey on Productivity at Work Outside Home and within the Household [abstract]. Arthritis. Rheumatol. 67 (2015).

33. Reveille JD. HLA-B27 and the seronegative Spondyloarthropathies. Am. J. Med. Sci. 316(4), 239249 (1998).

34. Abdelrahman MH, Mahdy S, Khanjar IA et al. Prevalence of HLA-B27 in patients with ankylosing spondylitis in Qatar. Int. J. Rheumatol. 8, 60213 (2012).

35. Elshishtawy H, Assaf N, Farouk N. Dickkopf-1 in ankylosing spondylitis: Relation to spinal dysmobility and radiographic findings. The Egyptian Rheumatologist. 34(3), 111-7 (2012).

36. Younsi R, Azrib S, Aitouazar M et al. Evaluation de l'incidence du gène HLA-B27 chez le patient atteint de spondylarthrite ankylosante au Maroc. Rev. Rhum. 74, 976-1037 (2007).

37. Gunal E, Sarvan F, Kamali $S$ et al. Low frequency of HLA-B27 in ankylosing spondylitis patients from Turkey. Joint. Bone. Spine. 75(3), 299-302 (2009).

38. Reveille JD. The genetic basis of spondyloarthritis. Ann. Rheum. Dis. 70, 44-50 (2011).

39. Ferna'ndez-Sueiro JL, Alonso C, Blanco FJ et al. Prevalence of HLA-B27 and subtypes of HLA-B27 associated with ankylosing spondylitis in Galicia, Spain. Clin. Exper. Rheumatol. 22(4), 465-468 (2004). 